\title{
Discovery of European frogbit (Hydrocharis morus- ranae L.) in Oconto County, Wisconsin: A summary of physical and plant community changes at a Lake Michigan coastal marsh
}

Ryne Douglas Rutherford ( $\nabla$ rdruther@mtu.edu )

Michigan Technological University School of Forest Resources and Environmental Science https://orcid.org/0000-0001-8185-9746

Jeremy Hartsock

University of Wisconsin-Superior

Nicholas Danz

University of Wisconsin-Superior

\section{Research Article}

Keywords: Great Lakes, Lake Michigan, Coastal Wetlands, Marsh, Plant Communities, European Frogbit

Posted Date: February 18th, 2022

DOI: https://doi.org/10.21203/rs.3.rs-1351299/v1

License: (c) (i) This work is licensed under a Creative Commons Attribution 4.0 International License.

Read Full License 


\section{Abstract}

Located in Oconto County, Wisconsin, Oconto Marsh \#2 is a Great Lakes Coastal Wetland Monitoring Program (CWMP) study site that borders the shoreline of Lake Michigan. Plant communities were characterized at Oconto Marsh \#2 along three fixed transects in 2011, 2016, 2017 and 2021, a period when Lake Michigan water levels increased by two meters. Transects were placed to intersect with three vegetation zones: submergent, emergent, and wet meadow. Here, we highlight physical landscape changes and the vegetation composition changes that occurred from 2011 to 2021 . From satellite imagery, we estimate the vegetated wetland area decreased by 50 percent. High energy wave action and ice scour penetrating farther inland are likely most responsible for causing these changes. Using multivariate ordination and PERMANOVA, we show plant composition in 2011 and 2021 was different from years 2016 and 2017. While invasive Phragmites australis was treated with herbicide in 2014 (herbicide treatment completed by non-CWMP groups), disturbance from progressively increasing water levels has facilitated considerable species turnover since monitoring began. Despite successful treatment of $P$. australis, the establishment of additional non-native species has caused site-wide mean coefficient of conservatism scores to decline from a calculated score of 4.2 in 2011 to 3.3 in 2021. Of critical importance, we discovered the highly invasive species European frogbit (EFB) (Hydrocharis morus-ranae L) near the research transects in 2021. This is the first documented occurrence of EFB in Wisconsin. The newly discovered EFB range spans $31 \mathrm{~km}$ along the general shoreline from Marinette to Oconto, WI.

\section{Introduction}

Initiated in 2011, the USEPA-funded Great Lakes Coastal Wetland Monitoring Program (CWMP) is a consortium of over 15 universities and government agencies collaborating to sample over 900 wetlands basin-wide over 5-year cycles (Uzarski et al. 2017). The information gathered on avian, anuran, fish, invertebrate, plant, and other environmental parameters is used to inform the public about Great Lakes coastal wetland health and to ensure restorative measures are effective. Additional CWMP objectives include identifying variation in wetland quality resulting from anthropogenic stressors, capturing wetland responses to natural disturbance (e.g., fluctuating water levels), and reporting non-native taxa to proper authorities.

In the northwest corner of Lake Michigan in Wisconsin, USA, extensive coastal wetland marshes bordering the shorelines of Green Bay account for a disproportionately large amount of Lake Michigan's total wetland area. Green Bay's coastal wetlands support numerous species and are important migratory stops for waterfowl and several species at risk (Albert and Minc 2004; Hohman et al. 2021; Prince et al. 1992). However, eutrophication of Green Bay's waters from surrounding agricultural lands, non-native species introductions, and high recreational use have contributed to the establishment and proliferation of non-native plants (Zedler and Kercher 2004). The continued spread of non-native taxa throughout Green Bay is a concern, as the financial burdens associated with managing invasive species are noteworthy, and long-term negative impacts on native biota is unclear. 
Since 2011, Lake Michigan water levels have experienced a period of substantially low water levels followed by a dramatic increase of approximately 2 meters (Figure 1). While Great Lakes coastal wetlands are adapted to cope with fluctuating water levels, the extreme water level changes that reached recorded record highs in 2020 have affected wetland plant distributions and reduced the total vegetated wetland area at several locations (Bourgeau-Chavez et al. 2021; https://mtu.maps.arcgis.com). In general, wetland vegetation guilds have shifted inland (Smith et al. 2020). While consecutive years with higherthan-average Lake Michigan water levels has imposed clear physical landscape changes to the shoreline at some coastal wetland sites, changes to the structure and floristic quality of wetland plant communities remain unclear. Moreover, given the number of wetlands already containing high abundances of nonnative plants throughout Green Bay (e.g., Eurasian watermilfoil, curly pondweed, hybrid cattail and narrow-leaved cattail, non-native common reed grass, reed canary grass), it is especially pertinent to determine whether prolonged exposure to recorded record-high water levels has facilitated further spread and (or) increased the dominance of non-native taxa in the region (Saltonstall, 2002; Trebitz and Taylor, 2007).

Below we report on the physical landscape and vegetation composition changes that occurred at a Green Bay coastal marsh in response to rising water levels. Our CWMP case-study site called Oconto Marsh \#2 was surveyed in years 2011, 2016, 2017, and 2021, we therefore have a natural experiment to better understand site-wide changes along a continuum of Lake Michigan water levels. Worth mentioning, in a non-experimental control effort, extensive Phragmites australis populations at the site were treated with herbicide in 2014. We have carefully considered the cumulative effects of management to remove a problematic invasive species in our interpretations of the data. Overall, we are most interested in 1) determining the extent of vegetated wetland area lost at Oconto Marsh \#2, and 2) exploring temporal plant diversity and floristic quality changes that occurred. At a local scale, our findings will inform on plant diversity changes that have likely happened at other exposed wetlands in Green Bay. At a basinwide scale, our observations will add to the literature seeking to better understand the cumulative impacts stemming from prolonged exposure to record-high Great Lakes water levels and highlight the success and potential consequences of invasive species management.

\section{Methods}

\section{Location and Climate}

Oconto Marsh \#2 is located in Oconto County, Wisconsin $(44.959,-87.797)$ and borders the shoreline of Lake Michigan. While the study site is a relatively small, narrow, and open lacustrine coastal wetland $\left(<1.2 \mathrm{~km}^{2}\right)$, it contains well-represented wet meadow, emergent, and submergent vegetation zones (Stanley et al. 2005; Johnston and Brown, 2013). Some characteristic Lake Michigan plant genera present within wet meadow, emergent, and submergent vegetation zones include Carex spp.,

Schoenoplectus spp., and aquatic floating-leaved Potamogeton spp., respectively (Albert et al. 2005). The plant communities that form coastal wetland vegetation zones generally sort out based upon their water- 
depth preferences (Sculthorpe 1967, Spence 1982, Kozlowski 1984). Further, these communities are dynamic, and may shift from one location to another in response to natural water level fluctuations (Smith et al. 2021).

Oconto Marsh \#2 is underlain by sandy soils and soil organic depth averages $23 \mathrm{~cm}$ in the wet meadow zones and $<3 \mathrm{~cm}$ in the emergent and submergent zones. A small unnamed stream bisects the site (Figure 1). Coinciding with our monitoring period, efforts by non-CWMP agencies to remove invasive Phragmites australis from the site using herbicide occurred in 2014.

Oconto County has a warm-summer humid continental climate (Köppen- Geiger Classification Dfb), with cold winters, warm summers, and no dry season (Kottek et al. 2006). According to the Midwestern Regional Climate Center (MRCC), monthly average temperature (1981-2010) at the nearest town, Oconto (10 km south), ranges from $-8.9^{\circ} \mathrm{C}\left(16.0^{\circ} \mathrm{F}\right)$ in January to $20.2^{\circ} \mathrm{C}\left(68.4^{\circ} \mathrm{F}\right)$ in July, with an annual average of $6.4^{\circ} \mathrm{C}\left(43.6^{\circ} \mathrm{F}\right)$. Average annual precipitation for Green Bay $(1981-2010)$ is $75.0 \mathrm{~cm}(29.52 \mathrm{in})$ (MRCC 2021).

\section{Wetland area calculation}

Wetland area calculations were estimated using the Google Earth polygon tracing tool and satellite imagery from years 2013 and 2018.

\section{Vegetation sampling}

Sampling methodology followed CWMP protocols described in Uzarski et al. (2017). Vegetation sampling was conducted in late June to mid-July $(7 / 11 / 2011 ; 6 / 27 / 2016 ; 7 / 11 / 2017 ; 7 / 18 / 2021)$ coinciding with maximum growth and reproductive periods for most plant species. Prior to accessing the site in 2011, three permanent transects to be resampled over subsequent years were drawn perpendicular to the shoreline using Google Earth satellite imagery (Figure 1). Transects were intentionally placed to intersect with the three vegetation zones present (i.e., wet meadow, emergent, and submergent vegetation).

In each year of monitoring, terminal transect start and end points are determined along the outer wetland edges. Along each transect, five evenly spaced sampling points per vegetation zone are defined in each year of sampling. The distance from the wetland edge to the first quadrat sampling point is $1 / 6^{\text {th }}$ the width of the vegetation zone. Vegetation sampling points are not fixed. Depending on the vegetation zone width, sampling points can shift farther inland or lakeward as wetland zones change over time. In cases where the vegetation zone is present but less than $11 \mathrm{~m}$ wide, a "narrow" sampling protocol is used. In this instance, the midpoint of the $<11 \mathrm{~m}$ wide vegetation zone is located along the original transect. At this midpoint, an additional transect is placed perpendicular to the original transect. Sampling points along the perpendicular transect (typically parallel to the shoreline) in the narrow zone are located at $5 \mathrm{~m}$ intervals from the zone midpoint along the original transect. 
Vegetation was surveyed in $1 \mathrm{~m}^{2}$ quadrats at each sampling point. Ideally, 45 sampling points would be present along the three transects ( 5 quadrats per zone, 15 sampling points per transect, $x 3$ transects). In each year of monitoring the site, totals of 25 to 45 quadrats were sampled along the transects depending on the number of vegetation zones present. All quadrats were placed $2 \mathrm{~m}$ to the right of the transect line to avoid trampling effects (Dybeic et al. 2020). Within each quadrat, all plant species were identified to lowest possible taxonomic unit (typically species). For plants unable to be identified in the field, representative specimens were collected and preserved for identification in the laboratory. At each quadrat, relative percent cover for each plant species, and water depth (distance from surface water to the soil surface) were recorded.

\section{Floristic quality analysis}

Gamma diversity (total species richness), mean coefficient of conservatism scores (Mean C), floristic quality index (FQI), and adjusted FQI were calculated for each year of sampling Oconto Marsh \#2 (Whittaker, 1972; Swink and Wilhelm, 1979). Useful for floristic quality analysis (FQA), coefficient of conservatism values are a numerical rating system ranging from 0 - 10 and used to describe individual species tolerance to disturbance and affinity to natural habitats. FQA using Mean $\mathrm{C}$ is a routine method to indicate ecological condition of plant communities at local, state, and national levels (Bourdaghs et al. 2006; DeBoer et al. 2011; Medley and Scozzafava, 2009; Dybeic et al. 2020). Low C-value species include ruderals and generalists capable of tolerating frequent disturbance. High C-value species are those with low tolerance to anthropogenic disturbance that require specific environmental conditions in less altered habitats. Non-native species are assigned a C-value of 0 . Rational for using Michigan coefficient of conservatism values for FQA at our Wisconsin site are 1) the Michigan C-value list is more complete for Great Lakes coastal wetland plants than any other Great Lakes state (i.e., more plant species have assigned C-values), and 2) the monitoring site resides less than $20 \mathrm{~km}$ from the Michigan border. FQI is calculated by multiplying the individual mean $\mathrm{C}$-values by the square root of the total number of species. FQI can be calculated for any scale, but it best used when comparing sites of similar area, as FQI increases with increasing richness (Spyreas, 2016). Adjusted FQI reduces the sensitivity to species richness and includes non-native species (Freyman, 2016).

\section{Statistical analyses}

To visualize dissimilarity between individual sampling point quadrats, plant species abundances (as untransformed percent cover data) were incorporated into a non-metric multi-dimensional scaling (NMDS) ordination using the program PC-ORD7 (NMDS design: Slow and thorough autopilot mode, BrayCurtis dissimilarity, Kruskal's secondary approach, 100 runs with real data). To determine site-wide temporal composition differences, percent cover values were incorporated into a one-way PERMANOVA analysis using year as a fixed factor ( $(\mathrm{a}=0.05)$ (Clarke and Gorley, 2006). 


\section{Results And Discussion \\ Landscape alterations}

The Oconto Marsh \#2 shoreline experienced considerable change over the monitoring period. From satellite imagery (years 2013 and 2018), we estimate the total vegetated wetland area decreased from 1.2 $\mathrm{km}^{2}$ in 2013 to $0.6 \mathrm{~km}^{2}$ in 2018 (Figure 1). Using the lake access walkway located between transects 2 and 3 as a point of reference, the walkway and shoreline vegetation (where the majority of 2011 wet meadow and emergent zone sampling points were placed) are largely absent from the 2018 satellite imagery (Figure 1b \& d). While we did observe wet meadow zone expansion farther inland in 2016 (discussed below), the total wetland area gained did not offset the area lost, because the wet meadows that developed are fragmented by uplands and housing settlements. The loss of vegetated wetland area farthest lakeward was almost certainly amplified by $P$. australis herbicide treatment in 2014 . Overall, we suggest that the combination of herbicide treatment and factors associated with higher water levels (e.g., high energy wave action and ice scour penetrating farther inland) are likely both responsible for causing shoreline alterations at the site. Tracking the return of vegetation back to its previous extent is a future monitoring objective.

\section{Water depths}

The lowest growing season (e.g., May to October) Lake Michigan water levels occurred in 2012 and 2013 (mean = 176.0 MASL) and the highest were in 2019 and 2020 (mean = 177.4 MASL) (Figure 1). Because several sampling points moved farther inland towards higher elevation areas in later years, the increase in water depths recorded at each sampling point do not entirely reflect the $>1$ meter water level increases that occurred. The shifting of coastal wetland plant guilds farther inland to maintain water depth preference in response to rising water levels was documented by Smith et al. (2020) for Lake Ontario coastal wetlands. In response to rising Lake Superior water levels, Hartsock et al. (2022) documented that a $100 \mathrm{~cm}$ increase in submergent zone water depths caused a reduction in submergent zone extent and a decline in aquatic macrophyte species richness at a coastal wetland in Superior, Wisconsin. At Oconto Marsh \#2, submergent and emergent zone water depths (measured within each quadrat) increased by about $35 \mathrm{~cm}$ from 2011 to 2021 (Figure 2). Because of these extreme water depth changes that occurred over a relatively short period, turnover in species composition should be expected (discussed below). Annual water depth changes were less extreme across the wet meadow zones. Water depths were highest in the wet meadow zones in 2017 (about $8 \mathrm{~cm}$ ), but generally were stable at near $0 \mathrm{~cm}$ over the entire study period, which was largely due to expansion of the wet meadow zone farther inland towards higher elevation areas.

\section{Transects and sampling points}


Table 1 summarizes the number of sampling points surveyed in each vegetation zone in each year. In 2011, all three transects had a definable submergent, emergent, and wet meadow vegetation zone, however, only 37 of the quadrats contained vegetation. Eight of 15 quadrats in the submergent zone were unvegetated in 2011. Sampling points in 2011 were located farther lakeward compared to later years and the emergent zone was less than 11 meters wide along transects 1 and 2, thereby warranting use of the narrow transect procedure (Figure 1). In 2016, a total of 35 sampling points were present along the transects and all sampling point quadrats contained vegetation. Submerged aquatic vegetation was present along transect 3 only. In accordance with the CWMP protocol, the transect 3 bearing shifted slightly to avoid sampling a shrub-dominated area. While the submergent zone extent decreased in 2016, emergent and wet meadow zones expanded and shifted farther inland following trends similar to those reported by Hartsock et al. (2022) and Smith et al. (2021). In contrast to 2011, all emergent zones along the transects exceeded 11 meters in 2016. Additionally, the farthest inland wet meadow sampling points in 2016 were over 50 meters farther inland compared to the 2011 farthest inland points. In 2017, due to a GPS malfunction, we were unable to display sampling point locations. Transect 2 was unable to be resampled in 2017 due to high water preventing safe access to the farthest lakeward areas. In total, 20 sampling points along transects 1 and 3 were sampled in 2017 and a submergent zone was not present along either of the two transects. In 2021, a total of 30 sampling points were sampled that were in similar locations as those from 2016. However, in contrast to 2017 observations, an emergent vegetation zone could not be defined along any of the three transects. Thus, between 2017 and 2021 there was turnover in plant composition at the farthest lakeward sampling points from an emergent vegetation-dominated community to a submerged aquatic-dominated community.

\section{Plant community dynamics}

A total of 101 vascular plant species were encountered during our four sampling campaigns at Oconto Marsh \#2. The complete species list is shown in Table S1. Table 2 shows the ten most abundant plant species within sampling point quadrats for all years Oconto Marsh \#2 was surveyed and mean relative cover. Total species richness was lowest in 2011 (32 species) and ranged from 52 to 56 species in years 2016, 2017 and 2021. Our observations of increasing species richness follow patterns from Lishawa et al. (2019) who documented plant richness increases after cattail removal at two Lake Huron marshes. However, some of our added species are likely due to sampling farther inland along the transects. Dominant species present in 2011 were notably dissimilar from later years (Table 2). Invasive $P$. australis was most abundant in 2011 with relative cover ranging from 5 to 70 percent when present in quadrats. Other dominant species in 2011 within the submergent, emergent, and wet meadow zones included Utricularia intermedia, Schoenoplectus pungens, and Carex stricta, respectively. Except for $C$. stricta, these species were less abundant in later years of monitoring. Following treatment of $P$. australis with herbicide in 2014, exposure to rising water levels, and subsequent loss of vegetated wetland area resulted in considerable species turnover at the site. Sampling point quadrats containing $P$. australis declined from 18 quadrats in 2011, 6 quadrats in 2016, and 3 quadrats in 2021. While P. australis was dominant across the site in 2011, dominant species in years 2016, 2017, and 2021 were mostly 
comprised of Calamagrostis canadensis, Phalaris arundinacea, Solidago canadensis, Potamogeton spp., and Stuckenia pectinata. P. australis was not encountered along the research transects in 2021, highlighting the success of management. However, despite reduction of $P$. australis cover, mean $\mathrm{C}$ and adjusted FQI progressively declined across the site from 2011 to 2021 (Table 3). This occurred because more non-native species were present in later years. In 2011, four non-native species were encountered: Lythrum salicaria, P. arundinacea, P. australis (invasive), and Typha angustifolia. In later years eight, additional non-native species were found that included: Cirsium palustre, Convolvulus arvensis, Equisetum arvense, Potentilla norvegica, Rumex crispus, Stellaria media, Typha x glauca, and Xanthium strumarium. Overall, higher proportions of low quality herbaceous and non-native species in years 2016, 2017, and 2021 are responsible for site-wide declines in floristic quality. Many plant species encountered in later years are typical colonizers of disturbed soils. Thus, the opening of niche space following $P$. australis treatment, repeat disturbance related to rising water levels, and a changing shoreline have likely facilitated establishment of several opportunistic and non-native species at Oconto Marsh \#2. Similar to our observations, Lishawa et al. (2019) reported an increase of early successional species in the wet meadow zone and a shift in the emergent zone community from a cattail-dominated community towards an aquatic macrophyte-dominated community following cattail removal at two Lake Huron marshes.

Ordinating the quadrat-based percent cover data using NMDS (3D stress $=2.0$ ) highlights the dissimilarity between several 2011 sampling points from those in later years (Figure 3). In general, 2011 sampling points are concentrated in the positive region of axis 1 and negative region of axis 3 . Overlaying dominant species on the ordination emphasizes the close association between several 2011 sampling points with U. intermedia and $P$. australis. Elevated cover of Juncus canadensis, Schoenopectus tabernaemontani and Leersia oryzoides in 2021 contributed to the dissimilarity between 2021 sampling points and the other years. Using year as a grouping factor, PERMANOVA analysis revealed years 2016 and 2017 were not different from each other, whereas years 2011 and 2021 were different from all other groups (Pseudo $F=3.4 ; p<0.001$ ). Overall, PERMANOVA and NMDS demonstrate considerable turnover in species composition has occurred. Species richness increased in the wet meadow areas after 2011 monitoring, and both emergent and submergent zones were in a state of flux as water levels progressively increased. While coastal wetlands are documented to be resilient ecosystems, prolonged exposure to recent record high Lake Michigan water levels over multiple growing seasons has potentially affected coastal wetland vegetation structure to a greater magnitude than other studies have shown. Treatment of $P$. australis with herbicide and its contribution to shoreline destabilization is also a factor not to be ignored. More studies aimed at assessing whether our observations of declining floristic quality and vegetated wetland area losses are the norm throughout Green Bay, or a unique circumstance should be encouraged.

\section{European frogbit}


An important added benefit of the CWMP is the total amount of wetland area observed by on-the-ground professional botanists while accessing and surveying research sites. In 2021, we discovered the invasive species European frogbit (EFB) (Hydrocharis morus-ranae L) at Oconto Marsh \#2 near the research transects, but not within the $1 \mathrm{~m}^{2}$ quadrats (Figure 4). Our observation of EFB is the first documented occurrence in the state of Wisconsin. EFB is a perennial free-floating aquatic plant native to parts of Europe, Asia, and Africa (Catling et al. 2003), but extremely invasive in Great Lakes wetlands. It is typically found in still or slow-moving aquatic habitats that include, but are not limited to ponds, ditches, marshes, canals, backwaters, and coastal wetlands. EFB can become dominant or co-dominant within five years after introduction and drastically alter aquatic ecosystems. Rapid growth in summer leads to formation of dense intertwined mats at the water's surface (Monks et al. 2019). Subsequent attenuation of available sunlight can negatively affect aquatic macrophytes below (Catling et al. 2003; Catling et al. 1988). While seed production is supposedly rare, EFB's rate of invasion is enhanced by asexual reproduction strategies that include stoloniferous growth and turion production. A single plant can produce up to 150 turions that are viable for up to two years (Catling et al. 2003). At Oconto Marsh \#2, several relatively small colonies of EFB were observed in open water areas within the south ditch adjacent to County Road Y (Figure 1), and additional EFB colonies were found in proximity to the bridge crossing. An unnamed stream that bisects the site and flows directly into Lake Michigan is likely facilitating the spread of EFB propagules to new areas. A voucher specimen from Oconto Marsh \#2 was collected and sent to the University of Michigan Herbarium (R.D. Rutherford $151 \mathrm{MICH}$ ) for documentation. EFB population coordinates were immediately reported to the Wisconsin Department of Natural Resources (WDNR). Action was taken by WDNR personnel to mitigate the EFB infestation and further investigation revealed the infestation range spanned from Oconto, WI (10 km south of the original discovery) to Marinette, WI (21 km northeast). Many infestation sites are state properties and state natural areas. Over 2,000 pounds of EFB was hand-pulled as of October 1,2021. The larger and more concentrated infestations are slated for treatment in early 2022 (Amanda Smith WDNR personal communication).

Across the Great Lakes basin, Lakes Ontario, Erie, and Huron have the most documented EFB observations, while Lake Michigan detections are more recent and less widespread. While no documented EFB observations are known for Lake Superior, its arrival is highly probable because EFB is present in the St. Marys River, the connecting channel between Lakes Huron and Superior (Dr. Dennis Albert personal observation, 2010). The presence of EFB in Lake Huron's Munuscong Bay in the eastern Upper Peninsula of Michigan has reduced the cover of several aquatic macrophytes, including common bladderwort (Utriculata vulgaris) (Monks et al. 2019, Wellons 2018). Robichaud and Rooney (2021) showed that following invasive $P$. australis removal from some Lake Erie coastal wetlands, EFB subsequently colonized the open water areas within two years. This is especially relevant to our study, as many Green Bay coastal wetlands have been treated with glyphosate-based herbicide to remove invasive $P$. australis with great success. However, some of these herbicide-treated sites have transitioned into open water wetlands. The opportunity for invasion by non-native colonizers such as EFB has already been documented at this and other sites. We recommend follow-up monitoring in areas treated with herbicide to mitigate recolonization by secondary invaders. 


\section{Conclusions}

We sought to evaluate both physical landscape and plant composition changes taking place at Oconto Marsh \#2 in response to rising Lake Michigan water levels that reached record-highs in 2020. A major landscape change was observed, with nearly 50 percent of vegetated wetland area loss from 2011 to 2021 , mostly across the emergent and submergent vegetation zones that currently remain in a state of flux. Loss of vegetated wetland area was likely driven by 1) deeper water drowning out emergent and meadow wetland plants, 2) wave action and ice scour penetrating further inland, and 3) shoreline destabilization following herbicide application to remove invasive $P$. australis. Despite near removal of invasive $P$. australis following treatment, site-wide floristic quality did not increase due to an increase in non-native species richness in the wet meadow zones and higher proportions of early successional herbaceous plants with lower assigned C-values in years 2016, 2017, and 2021. It is probable that other wetlands throughout Green Bay, especially for wetlands unable to expand further inland, have experienced similar reductions in total wetland area because of rising water levels with accompanying declines in floristic quality. Negative impacts on fauna forced to utilize narrower and (or) degraded submergent and emergent zones for habitat should be expected, but further studies are needed to corroborate these claims.

Of critical importance, we discovered highly invasive EFB near the research transects in 2021, the first documented occurrence of EFB in Wisconsin. The combination of region wide invasive Typha dominance (shown to facilitate EFB spread), novel habitats created by $P$. australis removal, and high-water levels have likely increased the range of habitat preferred by EFB in Green Bay. It is critical that the WDNR's efforts be sustained in what will likely be a multi-year effort to prevent the establishment of EFB throughout the Green Bay region.

Lastly, we provide an example highlighting the interacting consequences of record high Lake Michigan water levels, region-wide dominance by invasive plants (i.e., P. australis), and a net decline in habitat quality (based on the quality of plant communities) following the removal of an invasive species. While we do not have an answer for what can be done differently to resolve this decline in habitat following invasive-plant herbicide treatment, our CWMP mission to document long-term changes in coastal wetland health, ensure the effectiveness of restorative measures, capture wetland responses to natural disturbance, and report non-native taxa to proper authorities has been achieved here. A priority of future monitoring is to determine whether the previous emergent and submergent zone extents at Oconto Marsh \#2 will be recolonized by non-native species (e.g., invasive Typha spp., EFB, Myriophyllum spicatum) following recession of Lake Michigan water levels.

\section{Declarations}

\section{ACKNOWLEDGMENTS}


We thank Dr. Dennis Albert and Courtney Fung for reading the manuscript and providing helpful comments. We thank past field sampling crew members M. Jahnke, M. Hogfeldt, Nathan Dahlberg, and Jenny Rutherford. This work was funded by the Great Lakes Restoration Initiative as provided by the Great Lakes National Program Office of the United States Environmental Protection Agency, grant numbers GL-00E00612-0, 00E01567 and 00E02956. Although the research described in this work has been funded by the USEPA, it has not been subjected to the agency's required peer and policy review and therefore does not necessarily reflect the views of the agency and no official endorsement should be inferred.

\section{Funding:}

Funding for this work was provided by the Great Lakes National Program Office under the United States Environmental Protection Agency, grant number GL-00E00612-0 as part of the US federal government's Great Lakes Restoration Initiative.

\section{Conflicts of interest/ Competing interests:}

None

\section{Ethics approval:}

Not applicable

\section{Consent to participate:}

Not applicable

\section{Consent for publication:}

All authors give consent for the manuscript to be published in its current form

\section{Availability of data and material:}

Data will be made available upon request to the corresponding author

\section{Code availability:}

Not applicable 


\section{Authors' contributions}

R. Rutherford - Field work, wrote the manuscript, organized the data, created figures and tables

J. Hartsock - Field work,

N. Danz - Principal investigator, project conceptualization, assisted writing the manuscript

\section{References}

1. Albert DA, Minc LD (2004) Plants as regional indicators of Great Lakes coastal wetland health. Aquatic Ecosystem Health \& Management 7:233-247

2. Albert DA, Wilcox DA, Ingram JW, Thompson TA (2005) Hydrogeomorphic Classification for Great Lakes Coastal Wetlands. Journal of Great Lakes Research 31:129-146 doi:https://doi.org/10.1016/S0380-1330(05)70294-X

3. Bourgeau-Chavez LL, Graham J, Battaglia MJ, White L, Klassen J, VanderBilt DL, Poley AF, Pelletier K, Brisco B, Huberty B (2021) Great Lakes Remote Sensing ESRI Storymap, High resolution monitoring of coastal Great Lakes wetlands in 4D. https://mtu.maps.arcgis.com/apps/MapSeries/index.html? appid=2d06583e97844ea892413e2290 cbe885

4. Bourdaghs M, Johnston CA, Regal RR (2006) Properties and performance of the Floristic Quality Index in Great Lakes coastal wetlands. Wetlands 26:718-735 doi:10.1672/02775212(2006)26[718:PAPOTF]2.0.C0;2

5. Catling PM, Spicer K, Lefkovitch L (1988) Effects of the introduced floating vascular aquatic Hydrocharis morsus-ranae (Hydrocharitaceae), on some north American aquatic macrophytes. Naturaliste canadien 115:131-137

6. Catling PM, Mitrow G, Haber E, Posluszny U, Charlton WA (2003) The biology of Canadian weeds. 124. Hydrocharis morsus-ranae L. Canadian Journal of Plant Science 83:1001-1016 doi:10.4141/p02-033

7. Clarke, K.R., Gorley, R.N., 2006. PRIMER v6: User manual/ tutorial. PRIMER-E, Plymouth.

8. DeBoer LS, Rothrock PE, Reber RT, Namestnki SA (2011) The use of floristic quality assessment as a tool for monitoring wetland mitigations in Michigan The Michigan Botanist 50: 146-165

9. Dybiec JM, Albert DA, Danz NP, Wilcox DA, Uzarski DG (2020) Development of a preliminary vegetation-based indicator of ecosystem health for coastal wetlands of the Laurentian Great Lakes. Ecological Indicators 119:106768 doi:https://doi.org/10.1016/j.ecolind.2020.106768

10. Freyman WA, Masters LA, Packard S (2016) The Universal Floristic Quality Assessment (FQA) Calculator: An online tool for ecological assessment and monitoring. Methods in Ecology and Evolution 7:380-383 doi:https://doi.org/10.1111/2041-210X.12491

11. Hartsock JA, Schwarting RJ, Beaster K, Danz NP (2022) Coastal wetland plant community responses to record-high Lake Superior water levels: An Allouez Bay case study. Journal of Great Lakes 
Research: In review

12. Hohman TR et al. (2021) Influence of lake levels on water extent, interspersion, and marsh birds in Great Lakes coastal wetlands. Journal of Great Lakes Research 47:534-545 doi:https://doi.ogr/10.1016/j.jglr.2021.01.006

13. Johnston CA, Brown TN (2013) Water chemistry distinguishes wetland plant communities of the Great Lakes coast. Aquatic Botany 104:111-120 doi:https://doi.org/10.1016/j.aquabot.2012.08.005

14. Kozlowski TT, ed (1984) Flooding and Plant Growth. Academic Press, Orlando, Florida

15. Kottek M, Grieser J, Beck C, Rudolf C, Rubel F (2006) World map of the Köppen-Geiger climate classification updated Meteorologische Zeitschrift 15: 259-263

16. Lishawa SC, Lawrence BA, Albert DA, Larkin DJ, Tuchman NC (2019) Invasive species removal increases species and phylogenetic diversity of wetland plant communities. Ecology and Evolution 9: 6231- 6244. https://doi.org/10.1002/ece3.5188

17. Medley L, Scozzafava M (2009) Moving toward a national floristic quality assessment: considerations for the EPA National Wetland Condition Assessment National Wetlands Newsletter 31:6-9

18. Monks AM, Lishawa SC, Wellons KC, Albert DA, Mudrzynski BM, Wilcox DA (2019) European frogbit (Hydrocharis morsus-ranae) invasion facilitated by non-native cattails (Typha) in the Laurentian Great Lakes. Journal of Great Lakes Research

19. MRCC (2021) Climate summary for stations USC00476208 - Oconto 4 W, WI and USW00014898 Green Bay A S INTL AP, WI. Available at https://mrcc.illinois.edu/ mw_climate/climateSummaries/climSumm.jsp (Accessed October 25, 2021).

20. Prince HH, Padding PI, Knapton RW (1992) Waterfowl use of the Laurentian Great Lakes. Journal of Great Lakes Research 18:673-699

21. Robichaud CD, Rooney RC (2021) Effective suppression of established invasive Phragmites australis leads to secondary invasion in a coastal marsh Invasive Plant Science and Management 14:9-19, 11

22. Saltonstall K (2002) Cryptic invasion by a non-native genotype of the common reed, Phragmites australis, into North America Proceedings of the National Academy of Sciences 99:2445-2449 doi:10.1073/pnas.032477999

23. Sculthorpe CD (1967) The Biology of Aquatic Vascular Plants (reprinted in 1985). Edward Arnold, London

24. Smith IM, Fiorino GE, Grabas GP, Wilcox DA (2021) Wetland vegetation response to record-high Lake Ontario water levels. Journal of Great Lakes Research 47:160-167 doi:https://doi.org/10.1016/j.jglr.2020.10.013

25. Spence DHN (1982) The zonation of plants in freshwater lakes. Advances in Ecological Research $12: 37-125$ 
26. Spyreas G (2016) Scale and Sampling Effects on Floristic Quality. PLoS One 11:e0160693-e0160693 doi:10.1371/journal.pone.0160693

27. Stanley KE, Murphy PG, Prince HH, Burton TM (2005) Long-term Ecological Consequences of Anthropogenic Disturbance on Saginaw Bay Coastal Wet Meadow Vegetation. Journal of Great Lakes Research 31:147-159

28. Swink F, Wilhelm GS (1979) Plants of the Chicago Region, 3rd ed. Morton Arboretum, Lisle, IL. 922 pp.

29. Trebitz AS, Taylor DL (2007) Exotic and invasive aquatic plants in great lakes coastal wetlands: Distribution and relation to watershed land use and plant richness and cover. Journal of Great Lakes Research 33:705-721 doi:https://doi.org/10.3394/0380-1330(2007)33[705:EAIAPI]2.0.CO;2

30. Uzarski DG et al. (2017) standardized measures of coastal wetland condition: implementation at a laurentian great lakes basin-wide scale. Wetlands 37:15-32 doi:10.1007/s13157-016-0835-7

31. Wellons KC (2018) Ecophenology and control of European frogbit in a hybrid cattail marsh of the St. Marys River, Michigan. Master's thesis Oregon State University. https://ir.library.oregonstate.edu/concern/graduate_thesis_or_dissertations/7w62ff52m

32. Whittaker RH (1972) Evolution and measurement of species diversity Taxon 21, 213-251

33. Zedler JB, Kercher S (2004) Causes and consequences of invasive plants in wetlands: opportunities, opportunists, and outcomes. Critical Reviews in Plant Sciences 23:431-452 doi:10.1080/07352680490514673

\section{Tables}

\section{Table 1}

Summary table for the number of vegetation sampling points surveyed in each vegetation zone in each year along the three research transects. * Indicates that only 2 transects were sampled in 2017.

\begin{tabular}{lllll}
\hline Vegetation Zone & 2011 & 2016 & $2017^{*}$ & 2021 \\
\hline Wet meadow & 15 & 15 & 10 & 15 \\
\hline Emergent & 15 & 15 & 10 & 0 \\
\hline Submergent & 7 & 5 & 0 & 15 \\
\hline Totals & 37 & 35 & 20 & 30
\end{tabular}




\section{Table 2}

Ten most abundant plant species within sampling point quadrats for all years Oconto Marsh \#2 was surveyed. Values are mean percent cover scores \pm standard deviation.

\begin{tabular}{|c|c|c|c|c|c|}
\hline $\begin{array}{l}\text { Vegetation } \\
\text { zone }\end{array}$ & Species & 2011 & 2016 & 2017 & 2021 \\
\hline \multirow[t]{13}{*}{ Wet meadow } & $\begin{array}{l}\text { Phragmites australis } \\
\text { (invasive) }\end{array}$ & $\begin{array}{l}11.49 \pm \\
20.42\end{array}$ & $1.45 \pm 5.65$ & $\begin{array}{l}2.35 \pm \\
6.44\end{array}$ & $\begin{array}{l}11.49 \pm \\
20.42\end{array}$ \\
\hline & Phalaris arundinacea & & $\begin{array}{l}10.43 \pm \\
24.51\end{array}$ & $\begin{array}{l}9.85 \pm \\
15.51\end{array}$ & $2.33 \pm 9.71$ \\
\hline & $\begin{array}{l}\text { Calamagrostis } \\
\text { canadensis }\end{array}$ & & $\begin{array}{l}5.53 \pm \\
14.18\end{array}$ & $\begin{array}{l}6.80 \pm \\
13.28\end{array}$ & $\begin{array}{l}12.50 \pm \\
27.29\end{array}$ \\
\hline & Solidago canadensis & & $0.42 \pm 1.87$ & $\begin{array}{l}0.05 \pm \\
0.22\end{array}$ & \\
\hline & Carex lacustris & & $1.86 \pm 8.73$ & $\begin{array}{l}4.65 \pm \\
8.03\end{array}$ & $2.77 \pm 7.37$ \\
\hline & Carex stricta & $1.83 \pm 6.98$ & & & $1.50 \pm 4.58$ \\
\hline & Rubus strigosus & & $1.40 \pm 3.56$ & $\begin{array}{l}2.65 \pm \\
6.05\end{array}$ & \\
\hline & Juncus canadensis & & & & $\begin{array}{l}3.33 \pm \\
13.15\end{array}$ \\
\hline & Leersia oryzoides & & & & $3.23 \pm 9.53$ \\
\hline & Onoclea sensibilis & & $0.89 \pm 2.71$ & $\begin{array}{l}2.25 \pm \\
6.78\end{array}$ & \\
\hline & Bidens cernua & & & & $2.13 \pm 5.32$ \\
\hline & Lycopus americanus & $0.21 \pm 0.82$ & & & \\
\hline & Lythrum salicaria & $0.24 \pm 0.60$ & & & \\
\hline \multirow[t]{5}{*}{ Emergent } & Schoenoplectus pungens & $2.78 \pm 5.92$ & $1.94 \pm 5.56$ & & \\
\hline & Schoenoplectus tab. & $0.68 \pm 1.90$ & & & $2.97 \pm 8.24$ \\
\hline & Typha angustifolia & $1.56 \pm 3.79$ & & & \\
\hline & Bolboschoenus fluviatilis & $0.68 \pm 4.11$ & & & \\
\hline & Sparganium eurycarpum & & & $\begin{array}{l}0.85 \pm \\
2.66\end{array}$ & \\
\hline \multirow[t]{2}{*}{ Submergent } & Potamogeton pusillus & & $2.00 \pm 5.20$ & $\begin{array}{l}1.15 \pm \\
2.21\end{array}$ & \\
\hline & Potamogeton richardsonii & & & $\begin{array}{l}1.50 \pm \\
4.47\end{array}$ & $2.57 \pm 6.77$ \\
\hline
\end{tabular}




\section{Table 3}

Floristic quality analysis (FQA) for each year at Oconto Marsh.

\begin{tabular}{lllll}
\hline Conservatism-Based Metrics: & \multicolumn{1}{c}{2011} & 2016 & 2017 & 2021 \\
\hline Total Mean C: & 4.2 & 3.6 & 3.8 & 3.3 \\
\hline Native Mean C: & 4.4 & 4 & 4.2 & 3.7 \\
\hline Total FQI: & 23.8 & 26.7 & 27.1 & 23.6 \\
\hline Native FQI: & 24.1 & 28 & 28.5 & 25.1 \\
\hline Adjusted FQI: & 42.6 & 37.8 & 39.9 & 35.1 \\
\hline \% C value 0: & 9.4 & 14.5 & 11.8 & 15.7 \\
\hline \% C value 1-3: & 21.9 & 29.1 & 29.4 & 31.4 \\
\hline \% C value 4-6: & 59.4 & 47.3 & 49 & 51 \\
\hline \% C value 7-10: & 9.4 & 9.1 & 9.8 & 2 \\
\hline Native Tree Mean C: & $\mathrm{n} / \mathrm{a}$ & 1 & $\mathrm{n} / \mathrm{a}$ & $\mathrm{n} / \mathrm{a}$ \\
\hline Native Shrub Mean C: & $\mathrm{n} / \mathrm{a}$ & 3.7 & 3 & 4 \\
\hline Native Herbaceous Mean C: & 4.4 & 4.1 & 4.3 & 3.7
\end{tabular}

\section{Figures}

\section{Figure 1}

(A) Lake Michigan water levels (units in msl IGLD 85; Source: National Oceanic and Atmospheric Administration: https://tidesandcurrents.noaa.gov/). (B) Aerial photos of the Oconto Marsh \#2 and sampling points along research transects for years 2011, (C) 2016, and (D) 2018. Satellite imagery from Google Earth (years 2013, 2015, and 2018). Yellow circles at the transect terminal ends represent the original endpoints drawn in 2011 prior to visiting the site. County Road $\mathrm{Y}$ is shown in yellow. 


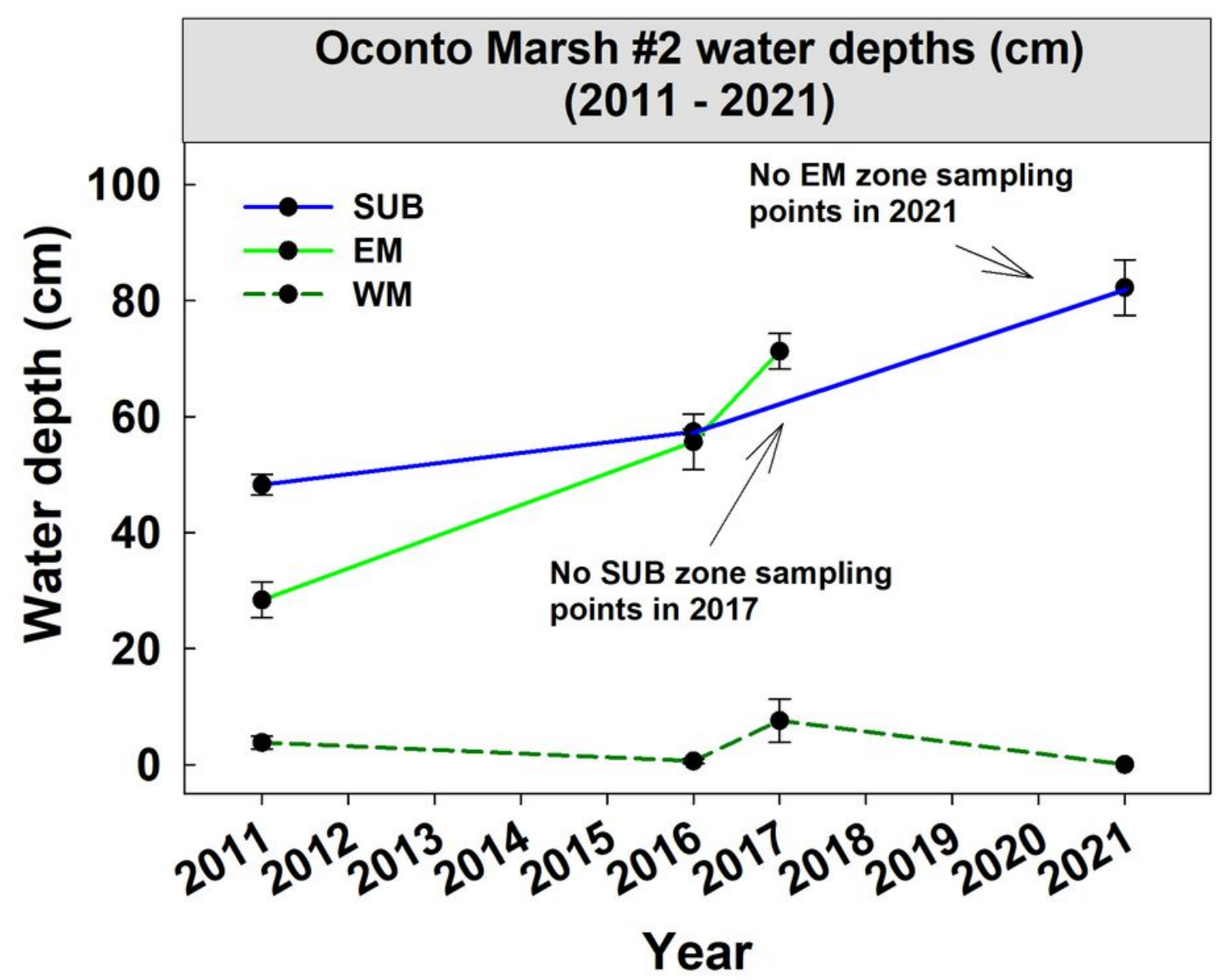

Figure 2

Sampling point water depths measured from within vegetation quadrats among vegetation zones (SUB = submergent; $\mathrm{EM}$ = emergent; $\mathrm{WM}$ = wet meadow). Error bars represent standard error. 


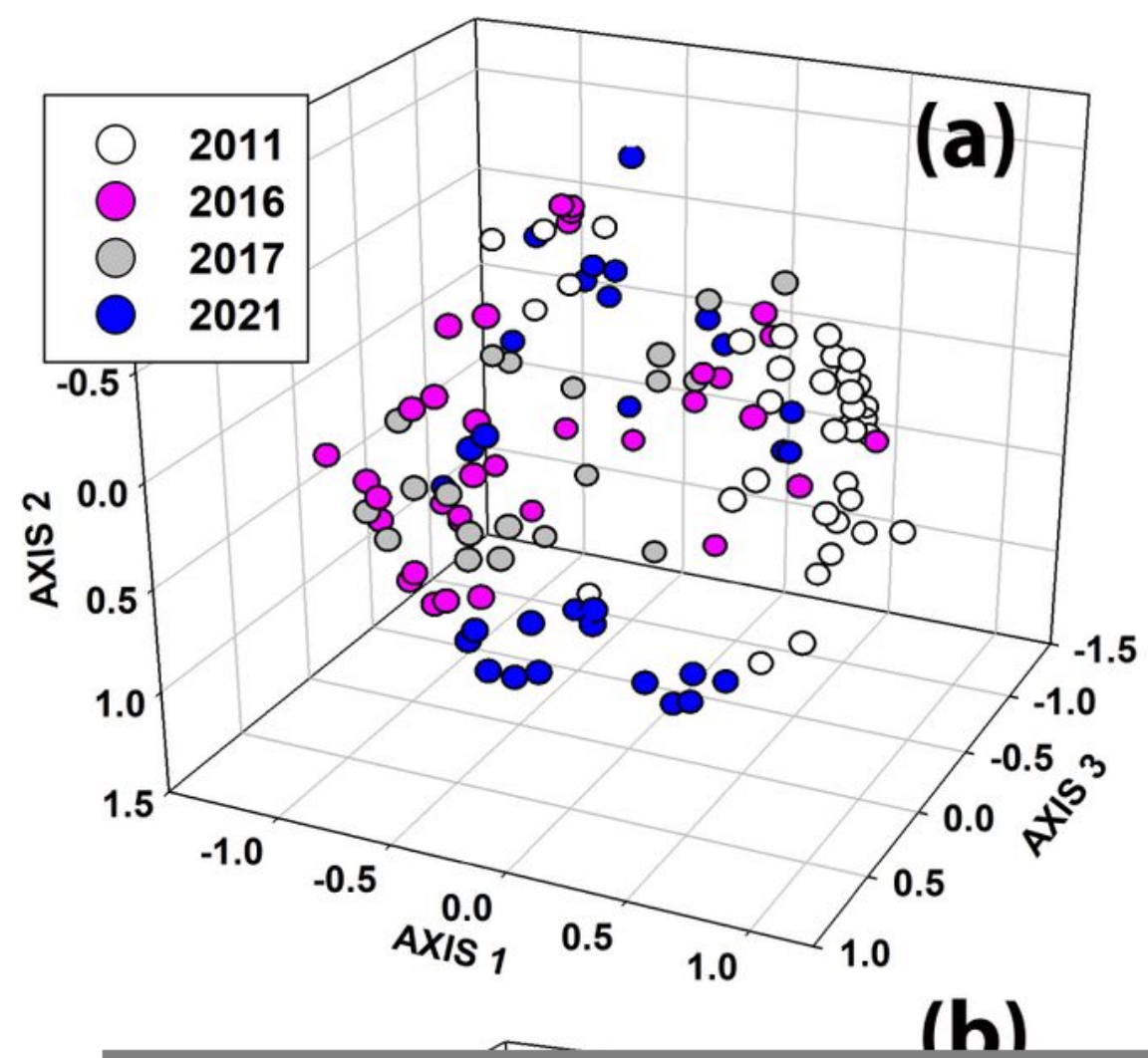

Figure 3

(A) NMDS displaying Oconto Marsh \#2 vegetation sampling points (3D stress $=0.2$ ). Using year as a fixed factor, PERMANOVA revealed groups 2011 and 2021 were different from all other groups. Groups 2016 and 2017 were not different from each other. (B) NMDS displaying Oconto Marsh \#2 dominant plant species. 
Figure 4

European frogbit (Hydrocharis morus-ranae L). Photograph by R.D. Rutherford.

\section{Supplementary Files}

This is a list of supplementary files associated with this preprint. Click to download.

- TableS10contomarshvascularplantandmacroalgaespecieslist.docx 